\title{
Severe psoriatic dactylitis: when psoriasis involves beyond the skin
}

\author{
H. Husein-ElAhmed \\ Department of Dermatology, Guadix Hospital, Granada, Spain
}

\begin{abstract}
To the Editor:
Psoriatic arthritis (PsA) is a distinct form of seronegative inflammatory arthritis occurring in $7-42 \%$ of patients with psoriasis (1). It is considered a multifactorial disease that may exhibit different clinical phenotypes such as peripheral arthritis, axial disease, dactylitis and enthesitis (2). Dactylitis is a hallmark manifestation of PsA and a key feature for its diagnosis, which occurs in 30 to $50 \%$ patients, commonly in early stages (3). Evidence is increasing that PsA patients may have a significant functional impairment, reduced quality of life and long-term disability (4), and thus recently guidelines have arisen for management of dactylitis (5).

We report an example of a farmer with a severe psoriatic dactylitis with impact on his work productivity and activity due this condition and who presented a satisfactory clinical response only after switching to a biologic agent.
\end{abstract}

A 57 year-old male presented with a 2 year history of swelling and pain in the dystal and proximal interfalangeal joints of third, fourth and fifth fingers in both hands associated with morning stiffness. Past medical history revealed hypertension controlled with daily enalapril $20 \mathrm{mg}$ and a 30-year history of palmoplantar psoriasis treated with weekly methotrexate $20 \mathrm{mg}$ and topical high-potency steroids. Clinical examination revealed severe dactylitis in digits (sausage fingers) associated with ungueal hyperkeratosis and onycholysis (Figure 1). Despite the therapy, erythematous scaly plaques of psoriasis were present in palms and soles. The patient was a farmer and he was unable to work due to symptoms for almost one year.

Although it was originally considered a benign condition, PsA is now recognized as a serious, debilitating, progressive and destructive disease with a significant psychological, social and functional impact. The most prevalent form of PsA is the asymmetric oligoarticular arthritis, which involves small peripheral joints, particularly the distal interphalangeal joints. Thus, disability in the workplace is very common in population with severe PsA (6), and it has a significant effect on the patient's quality of life and financial status. Classification criteria for PsA have set the specificity of dactylitis as one of the most discriminative musculoskeletal manifestation $(7,8)$, and for yet unclear reasons, the risk for developing erosions in PsA seems to be higher in patients with dactylitis in comparison with those who show only arthritis (9).

Traditionally, therapeutic approaches are not based on well-designed trials, but on empirical experiences. Physicians use drugs such as non-steroidal antinflammatory drugs, local corticosteroid injections, metotrexate, cyclosporine and azathioprine (10). However, controlling symptoms cannot be achieved in all cases and the introduction of anti-tumor necrosis factor (TNF)-alpha therapies is required. Treatment with TNF-alpha inhibitors may result in not only substantial improvements in signs and symptoms of skin and nail diseases, but also improvements in all distinct sites of joint diseases such as axial arthritis, enthesitis and dactylitis (10). Since metotrexate was not effective in our patient, it was discontinued and azathioprine $1 \mathrm{mg} /$ $\mathrm{kg}$ was initiated. Three months later, the symptoms were barely controlled and at this point, infliximab $5 \mathrm{mg} / \mathrm{kg}$ was started (at $0,4,8$, and 12 weeks) and the morning stiffness and pain decreased dramatically after the first infusion. With the second infusion, the swelling disappeared. At this 
point, azathioprine was discontinued and a maintenance therapy based only on infliximab was established with infusions every 8 weeks. The patient is back at work and no relapse has been observed during the two years of follow-up. This case highlights the notable impact of dactylitis on work place and quality of life in psoriatic patients and the efficacy of the TNF-alpha therapies in cases where outcomes are not satisfactory with classic drugs. Although efficacy of anti-TNFs seems to be independent of synthetic disease-modifying anti-rheumatic drugs, suggesting only a minor role of combination therapy in PsA (11), we decided to keep the azathioprine in combination with infliximab until the swelling was completely resolved.

The limited data on dactylitis researches warrants the need for randomized trials, with psoriatic dactylitis as a primary outcome, to determine a valid, reliable, and clinical algorithm for PsA patients with dactylitis in order to achieve prolonged remission and prevention of irreversible bone damage.

Conflict of interest: the author declares no potential conflict of interest.

\section{REEFERENCES}

1. Wilson FC, Icen M, Crowson CS, et al. Incidence and clinical predictors of psoriatic arthritis in patients with psoriasis: a populationbased study. Arthritis Rheum. 2009; 61: 233-9.

2. Eder L, Gladman DD. Psoriatic arthritis: phenotypic variance and nosology. Curr Rheumatol Rep. 2013; 15: 316.

3. Veale D, Rogers S, Fitzgerald O. Classification of clinical subsets in psoriatic arthritis. $\mathrm{Br}$ J Rheumatol. 1994; 33: 133-8.

4. Ackermann C, Kavanaugh A. Economic burden of psoriatic arthritis. Pharmacoeconomics. 2008; 26: 121-9.

5. Coates LC, Kavanaugh A, Mease PJ, et al.

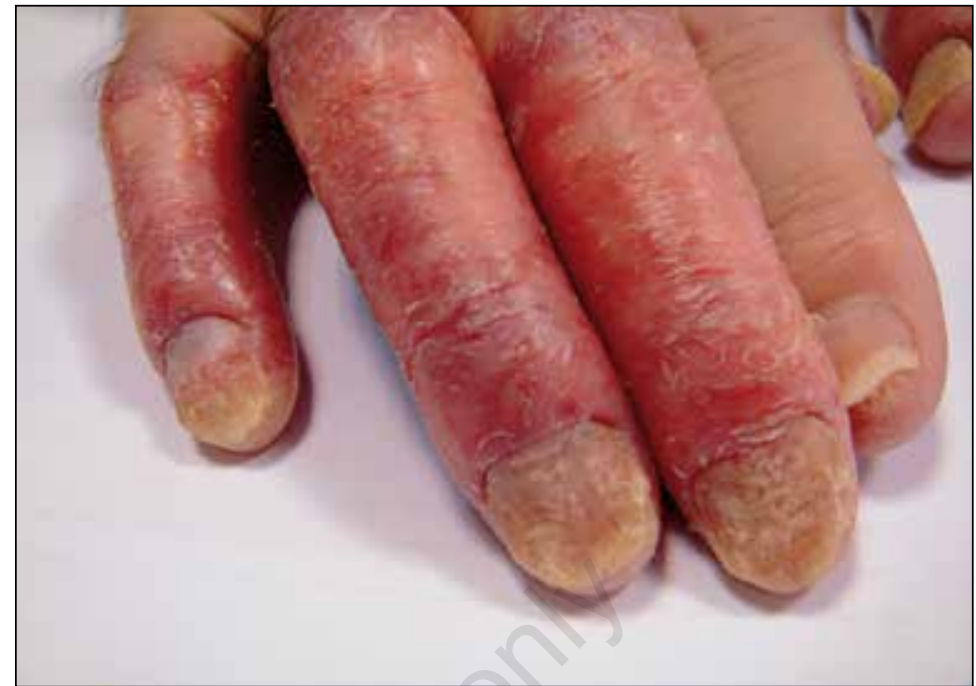

Figure 1 - Dactylitis involving the third, fourth and fifth fingers of the right hand in both distal and proximal interfalangeal joints associated with skin and ungueal affections. Scaly and erythematous psoriatic plaques are observed with onycholysis and ungueal hyperkeratosis.

Group for Research and Assessment of Psoriasis and Psoriatic Arthritis 2015 treatment recommendations for psoriatic arthritis. Arthritis Rheumatol. 2016; 68: 1060-71.

6. Tillett W, de-Vries C, McHugh NJ. Work disability in psoriatic arthritis-a systematic review. Rheumatology (Oxford). 2012; 51: 275-83.

7. Taylor W, Gladman D, Helliwell P, et al. Classification criteria for psoriatic arthritis: development of new criteria from a large international study. Arthritis Rheum. 2006; 54: 2665-73.

8. Brockbank JE, Stein M, Schentag CT, Gladman DD. Dactylitis in psoriatic arthritis: a marker for disease severity? Ann Rheum Dis. 2005; 64: 188-90.

9. Vieira-Sousa E, Alves P. Dactylitis: more than just arthritis. Acta Reumatol Port. 2015; 40: 210-2.

10. Rose S, Toloza S, Bautista-Molano W, Helliwell PS. Comprehensive treatment of dactylitis in psoriatic arthritis. J Rheumatol. 2014; 41: 2295-300

11. Kocijan R, Muschitz C, Rech J. Biological agents in psoriatic arthritis. Wien Med Wochenschr. 2015; 165: 36-9. 